\title{
Design and Verification of an On-Body Antenna in the Harsh Environment of a Horse Hoof
}

\author{
Jasper Goethals*, Denys Nikolayev ${ }^{\dagger}$, Arno Thielens*, Gunter Vermeeren* Leen Verloock*, Margot Deruyck*, \\ Luc Martens* Wout Joseph* \\ ${ }^{*}$ Department of Information Technology, Ghent University, IMEC, WAVES, Ghent, Belgium, \\ jasper.goethals@ugent.be \\ ${ }^{\dagger}$ IETR - UMR 6164, Univ Rennes, CNRS, Rennes, France
}

\begin{abstract}
This paper describes the design of an antenna embedded in a hoof pad. The operating frequencies are within the GSM900 band. The dimensions are $40 \mathrm{~mm} \times 25 \mathrm{~mm} \times 1.55 \mathrm{~mm}$. During the characterization of the antenna, the dynamic and harsh environment of a horse hoof is taken into account. The antenna impedance is validated numerically and experimentally to be robust to these changes.
\end{abstract}

Index Terms-Antenna, animal applications, body area network, GSM900, on-body, PIFA, robustness.

\section{INTRODUCTION}

Owning a horse is not only a serious financial undertaking, but also an emotional investment due to the strong trust bond between a horse and its rider, protecting the health of this valuable asset is thus of utmost importance. The earlier an anomaly is detected, the higher the chances for a full recovery. To monitor the horse's vital parameters, one can put a monitoring device or a wearable on the animal, which will inform the caretaker in an early stage about any possible anomaly [1]. This requires a wireless connection from the device to a gateway, e.g. installed in the stable. Such a wearable must of course not harm the horse (exclude chafing, tendon damage, etc.) or hinder movement, while at the same time the device should be protected from any damage by the horse (e.g. biting). Many existing wearables fail on these requirements by placing the monitoring devices on the head or torso of the horse [2], [3]. In particular, the horse's legs are very delicate due to the many tendons, and, for this reason, no cables nor any other kind of bulky electronics like a battery pack should be attached to them. One way to address this issue is to place a wearable under the hoof inside a thin pad like the sole in a shoe (made of leather or silicone). This pad is attached to the hoof through the nails of the horseshoe and feels naturally for the horse since these pads are today often used to solve orthopedic issues. Fig. 1 shows a horseshoe attached without (left) and with (right) a hoof pad. Note that the frog (V-shape visible in the left figure) is considered to be the hoof's weak part and cannot be covered by any electronics, hence limiting the size of the electronics and antenna.

The goal of this study is to develop a wireless off-body telemetry device that operates from inside the hoof and sends the data to a cellular gateway. To cover sufficiently long

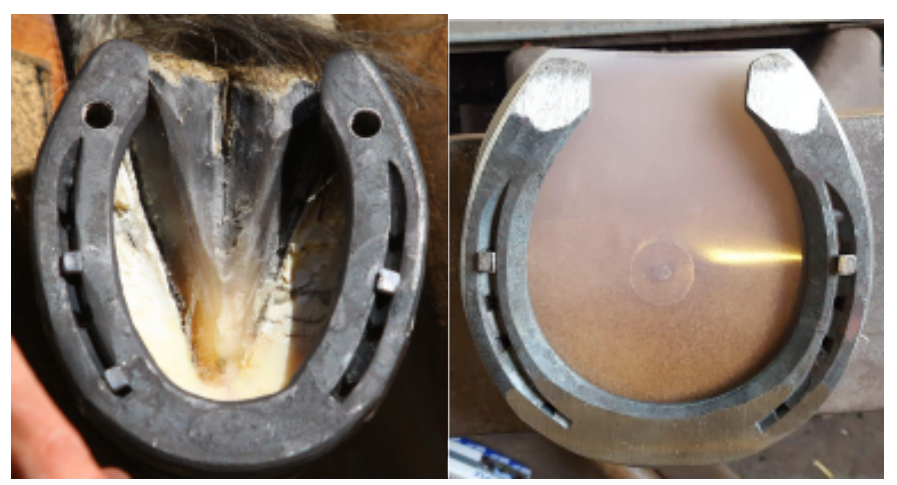

Fig. 1. Example of a horseshoe without (left) and with a pad (right) on the hoof [4], [5]

ranges during training and recreational activities and to be able to communicate directly from the horse to a gateway, radio technologies with suitable propagation characteristics need to be used. Lower frequency waves are typically associated with larger achievable ranges. However, lower radio frequencies typically require larger antennas, and limit the maximum achievable throughput, thereby limiting device placement options and the amount of monitoring data, respectively. Here, we chose to use the $900-\mathrm{MHz}$ operating band that allows using Global System for Mobile Communications (GSM) and LongTerm Evolution (LTE) technologies (942 MHz - $960 \mathrm{MHz}$ ). Conductive objects (such as horseshoe) located in the near field strongly affect the antenna radiation performance [6]. In addition, proximity of dielectric objects (horse's hoof) impact both the impedance and radiation performances [7], [8]. In this work, we explore an antenna design constrained by the aforementioned factors of operation in the harsh environment of a horse hoof. This paper is organized as follows: Section II focuses on the antenna design considerations and the scenarios incorporating the moving aspects, the modeling approaches, the materials, and the measurement setup on the real horse leg. The results are presented in Section III. Section IV concludes the paper. 


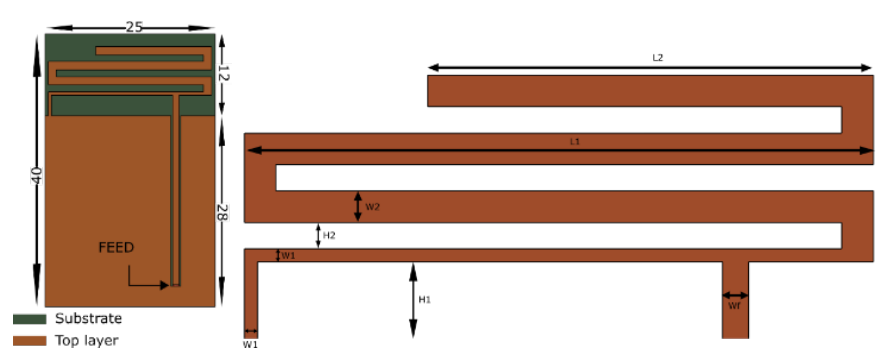

Fig. 2. The PCB layout (left) and the dimensions of the antenna (right) with parameters values: $\mathrm{W} 1=0.5, \mathrm{~W} 2=1.2, \mathrm{Wf}=1, \mathrm{~h} 1=3, \mathrm{~h} 2=1, \mathrm{~L} 1=24$, $\mathrm{L} 2=17$. All dimensions are in $\mathrm{mm}$.

\section{MEthodS}

\section{A. Antenna Design}

The antenna design has to comply with the spatial constrains of the device. In this work, the antenna is embedded in a large hoof pad with dimensions $135 \mathrm{~mm} \times 150 \mathrm{~mm} \times 4$ $\mathrm{mm}$, as depicted in Fig. 1. A hoof pad is usually a thin sheet of leather, plastic or silicon used to prevent rocks or uneven hard surface hurting the bottom of the hoof. A border of around $2 \mathrm{~cm}$ has to be kept clear around the edge of the hoof, where the horseshoe will press the pad against the hoof. Between the pad and the hoof, an elastic epoxy resin is applied. This fills the cavity constructed by the pad and the hoof. The epoxy is applied to prevent dirt and rocks to agitate the sensitive hoof area while wearing the pad and horseshoe. The thickness of this layer depends on the horse. For example, a flat footed horse will not form this cavity. The parameters of interest are the reflection coefficient, bandwidth (BW) at $|\mathrm{S} 11|=-10 \mathrm{~dB}$, center frequency, the radiation efficiency and gain of the antenna. Based on the geometrical limitations of the space in the hoof pad (i $0.01 \lambda$ in height), antennas types that are suitable for the considered applications should be of a low profile. Considering the required miniaturization, the choice was made to persue an inverted-F antenna design (IFA). The printed IFA can be easily manufactured in a mechanically robust configuration since it does not require vertical shorting strips or vias that reduce the rigidity of the structure. Fig. 2 shows the antenna layout based on our previous paper [9]. The placement of the feed can be used to match the antenna to a $50-\mathrm{Ohm}$ feed on the pad where the RF frontend in located without using discrete components. The dimensions of the board are $40 \times 25 \times 1.55 \mathrm{~mm}^{3}$ (corresponding to $0.07 \lambda \times$ $0.12 \lambda \times 0.01 \lambda$ ) hence fulfilling the constrains of the device. The antenna itself is $12 \times 25 \mathrm{~mm}^{2}$. The substrate material for a prototype is FR-4 $\left(\epsilon_{r}=4, \sigma=0.0038 \mathrm{~S} / \mathrm{m}\right)$ [10], which is chosen for its low manufacturing cost [11]. However, more durable and shock-resistant substrates with comparable EM properties could be employed for the finalized design. All metallization is modeled as perfect electrical conductor (PEC). The dimensions are denoted on the schematic of the antenna on Fig. 2(right). During the design, the environmental properties and elements were incorporated and studied one by one to quantify their effects on the antenna performance.
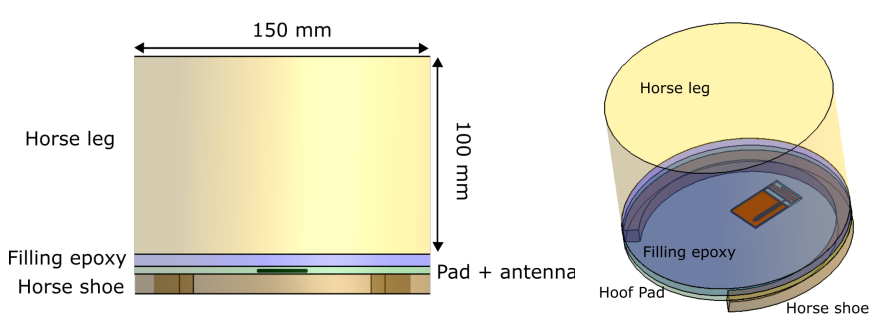

Fig. 3. The complete setup from view(left), perspective view (right).

\section{B. Application Scenarios}

The environment of a horse leg is dynamic. When the horse is in the meadow, it will not only graze, but also walk, trot, gallop, and it might even buck. Since the monitoring device is placed in the hoof pad, the antenna environment will also change dynamically. In this paper, two main scenarios are considered. In the first, the horse has his hoof lifted off the ground. The angle of the front hoof in the air is determined (based on the work done in [12]) to be 90 degrees with respect to the ground and lifted $10 \mathrm{~cm}$ during a normal walk (so called working step). During this first raised scenario, the leg will be in free space, thus the effect of the soil on the antenna near field could be neglected. In the second scenario, the hoof is on the ground. The soil is modeled by a $500 \times$ $500 \times 50 \mathrm{~mm}^{3}$ block. In this study, we consider the grass and concrete. Grass was assigned a relative permittivity of 8 and a conductivity $0.163 \mathrm{~S} / \mathrm{m}$ [13], whereas concrete was assigned a relative permittivity of 4.5 and a conductivity of $6.25 \mathrm{mS} / \mathrm{m}$ [14]. Furthermore, the epoxy layer thickness will vary from horse to horse. To study the dependence of this layer, different thicknesses were simulated.

\section{Numerical Model}

The antenna is embedded in the pad that consist of polylactic acid (PLA) and epoxy $\left(\epsilon_{r}=3.5, \sigma=0.0023 \mathrm{~S} / \mathrm{m}\right)$ [15]. In the simulations, the PLA and the epoxy have the same EM properties. This encapsulation will increase the robustness of the parameters of the antenna to the influence of the horse leg and the ground and is necessary for the mechanical stability of the pad. Fig. 3 shows the complete configuration. A horse's leg is simulated by a $10-\mathrm{cm}-$ long cylinder. The complete setup is built by the four layers: the horseshoe, the pad, the filling epoxy and the leg. We assume that the leg is made out of bone (homogeneous) $\left(\epsilon_{r}=12, \sigma=0.78 \mathrm{~S} / \mathrm{m}\right)$ with parameters similar to human bone [16]. However, another simulation with the horse leg out of muscle $\left(\epsilon_{r}=51, \sigma=2.2 \mathrm{~S} / \mathrm{m}\right)$ is performed to quantify the effect of the variation of environment EM properties. The horseshoe is modelled as PEC. The antenna is tuned to the scenario where the leg is in the air and is made out of bone, and the filling epoxy is $5 \mathrm{~mm}$ thick. The numerical simulation are performed using Sim4Life(S4L), a finite-difference time-domain (FDTD) simulator [17]. For the calculation of the BW and center frequency, a Gaussian signal was excited over the edge source at the feed strip. The center 


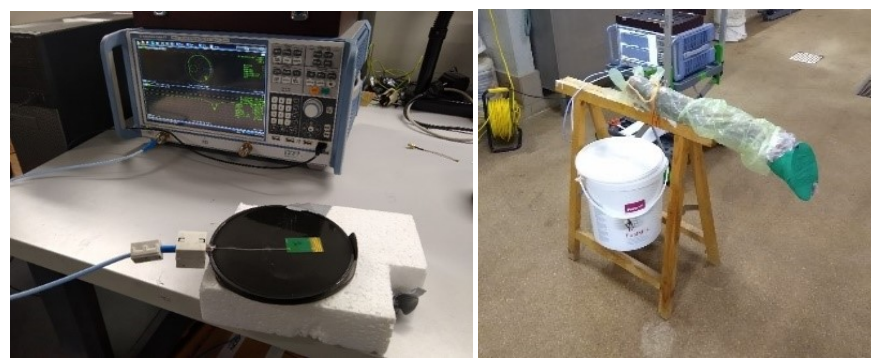

Fig. 4. The constructed pad (Left), the severed horse leg, covered in a hygienic veterinary glove. The part of the hoof is uncovered from the glove and the hoof pad is attached to it with tape. The cavity created between the hoof pad and the hoof is filled with Equi-pak. (Right)

frequency of this Gaussian signal is $1 \mathrm{GHz}$, and the BW is $1 \mathrm{GHz}$. The soil block terminates into perfectly matching layers. In the second step, the simulations are performed with a harmonic excitation to calculate the efficiency and the reflection coefficient. The number of cells of the grid were 1.61 MCells and 2.04 MCells for the BW simulations without or with ground, respectively, and 1.43 MCells and 1.64 MCels for the gain pattern simulations without or with ground, respectively.

\section{Experimental Setup Using a Real Horse Leg}

The produced pad is seen in Fig. 4 (left). A miniature X.FL [18] connection is included to connect the antenna to the test bench with a 50-Ohm feedline. The pad is constructed by $3 \mathrm{D}$-printing a $15-\mathrm{cm}$ diameter cylinder of $1-\mathrm{mm}$ height and a border of $4 \mathrm{~mm}$. A small holder for the $4 \times 2.5 \mathrm{~cm}$ PCB is also printed with PLA. This pad is then filled with epoxy resin to finish the pad as a solid cylinder with the antenna PCB embedded. To finalize the experimental validation, the previous measurement are repeated on a real horse leg. A leg of a recently deceased horse $(<24$ hours) was severed and provided by the faculty of veterinary medicine at Ghent University. The PLA-epoxy hoof pad with the embedded antenna was attached using tape. Next, the hoof iron was attached over this ensemble with more tape. Between the hoof pad and the hoof, a cavity is formed due to the physiology of a horse hoof. This cavity was filled with epoxy Equi-pak [19]. The farrier usually does this to prevent dirt to enter this cavity and consequently prevent inflammation of the hoof tissue. In the test setup, the horse hoof is at a height of $64 \mathrm{~cm}$ from the ground and hold by a wooden trestle. A plastic bucket with horse feed is used as counter weight, as depicted on Fig. 4(right). The measurements were done at a surgical stable at the faculty of veterinary medicine. Besides the free space measurements, different soil types were examined by pressing the hoof gently on the surface by its own weight. Again, grass and concrete were considered.
TABLE I

THE SIMULATED RESULTS FOR THE BASIC SETUP FOR DIFFERENT LEG PARAMETERS (BW AND $f_{0}$ ARE IN MHz)

\begin{tabular}{|c||c|c|c|c|}
\hline $\begin{array}{c}\text { Tissue } \\
\text { thickness epoxy }\end{array}$ & $\begin{array}{c}\text { Bone } \\
5 \mathrm{~mm}\end{array}$ & $\begin{array}{c}\text { Muscle } \\
5 \mathrm{~mm}\end{array}$ & $\begin{array}{c}\text { Bone } \\
3 \mathrm{~mm}\end{array}$ & $\begin{array}{c}\text { Bone } \\
7 \mathrm{~mm}\end{array}$ \\
\hline$\epsilon_{r} /$ sigma $[\mathrm{S} / \mathrm{m}]$ & $12 / 0.78$ & $51 / 2.2$ & $12 / 0.78$ & $12 / 0.78$ \\
\hline $\mathrm{BW}$ & $932-1006$ & $921-979$ & $901-983$ & $932-1000$ \\
\hline $\mathrm{f}_{0}$ & 968 & 955 & 942 & 976 \\
\hline$\eta_{\mathrm{rad}}$ & $8.8 \%$ & $2.3 \%$ & $8.1 \%$ & $9.8 \%$ \\
\hline
\end{tabular}

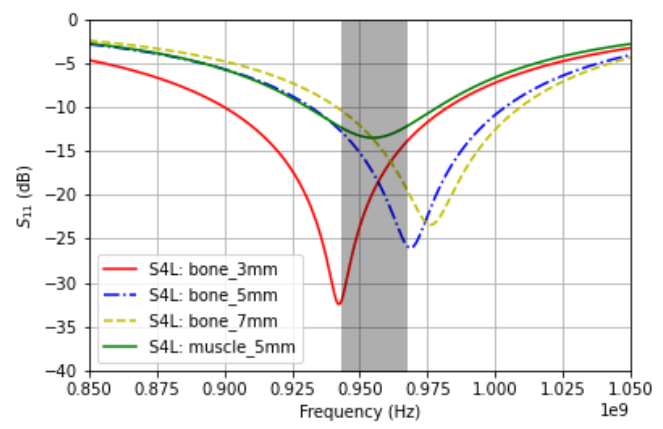

Fig. 5. $|\mathrm{S} 11|$ plot of the different leg tissues and filling epoxy thickness. The gray band denotes the aimed frequency band.

\section{RESULTS}

\section{A. Numerical Results}

1) Baseline results: The first configuration is for the lifted hoof. The leg is simulated with bone parameters. Fig. 5 shows the reflection coefficient. Table 1 summarizes the results. The simulation shows that the bone setup is well matched for the aimed band. Different tissues will shift the resonance to lower frequencies, which is easily explained by the higher permittivity of these materials. Table 1 shows that the efficiency lowers significantly with tissue like muscle that has a higher conductivity in comparison with bone. The low efficiency of $<10 \%$ is due to the tissue dense environment of the antenna. Furthermore, the thickness of the filling epoxy has a significant influence on the tuning of the antenna. Fig. 5 shows that the antenna is robust against variations in the filling epoxy thickness. The aimed band is still served with deviation of $2 \mathrm{~mm}$ in thickness.

2) Influence of the Soil: Fig. 6 shows the influence of the different soil types. We can conclude that the antenna is robust against the change in soil type according to the simulations. Variation of less than $0.01 \%$ and only a slight detuning are noted. This is necessary to have to achieve a stable horse hoof to gateway communication.

\section{B. Experimental Results}

Fig. 7 shows the results of the horse measurements. A good agreement between the simulations and the experiment is obtained ( $<3 \%$ difference in resonance frequency). The robustness to the different soil types is confirmed. The mismatch is explained by the thickness of the filling epoxy and the unknown parameters of the horse leg. The horse leg physiology 


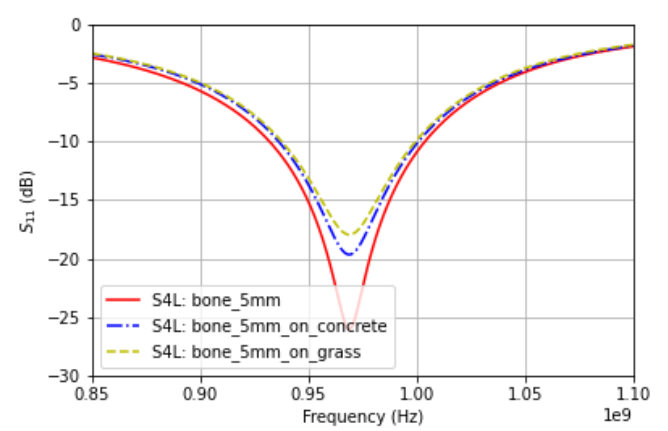

Fig. 6. Influence of the soil type on the $|\mathrm{S} 11|$ measurement.

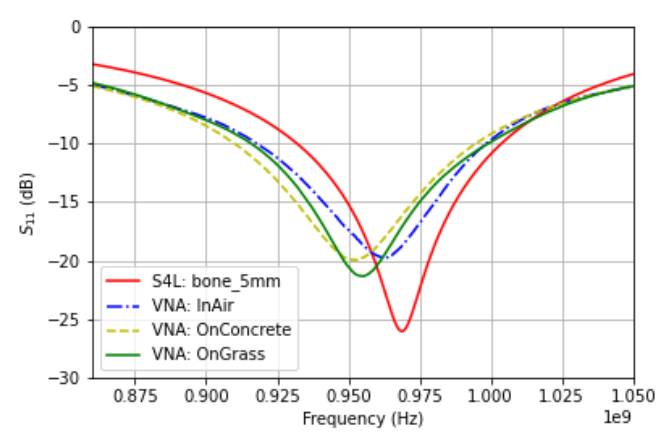

Fig. 7. The $|\mathrm{S} 11|$ measurement on the horse leg. VNA label denotes the experimental measurements. S4L label denoted the simulation results for reference.

(hoof is mostly a bony structure) shows that the thickness of the epoxy will have the highest sensitivity for the antenna performance. The off-set in $|\mathrm{S} 11|$ is due to the loss in the X.Fl wire.

\section{CONCLUSiON}

In this paper, we have established an antenna in a hoof-pad working in the desired frequency band. We have experimentally validated the simulations with real horse measurements. We found a very good agreement between measurements and simulations in the air $(<3 \%$ difference in resonance frequency). The antenna is robust against the soil type, but has a dependence on the thickness of the filling epoxy. Future work will be on investigating the robustness and performance by varying tissue parameters of different horses.

\section{ACKNOWLEDGMENT}

This work was executed within the imec.icon project HoofMATE, a research project bringing together academic researchers and industry partners. The Hoof-MATE project was co-financed by imec and received project support from Flanders Innovation \& Entrepreneurship (project nr. HBC.2018.0536).

M. Deruyck and A. Thielens are post-doctoral fellows of the FWO-V (Research Foundation - Flanders).

\section{REFERENCES}

[1] C. Hartmann, L. Lidauer, J. Aurich, C. Aurich, and C. Nagel, "Detection of the time of foaling by accelerometer technique in horses (Equus caballus )-a pilot study," Reproduction in Domestic Animals, vol. 53 pp. 1279-1286, Dec. 2018.

[2] "Equisense Motion."

[3] "Ekico • Leader in horses hooves monitoring tools."

[4] J. Boris, "How to Remove a Horseshoe," June 2015. Library Catalog: www.farmandfleet.com.

[5] "Podi Artist - Startpagina."

[6] E. Tanghe, W. Joseph, P. Ruckebusch, L. Martens, and I. Moerman, "Intra-, Inter-, and Extra-Container Path Loss for Shipping Container Monitoring Systems," IEEE Antennas and Wireless Propagation Letters, vol. 11, pp. 889-892, 2012.

[7] D. Nikolayev, W. Joseph, M. Zhadobov, R. Sauleau, and L. Martens, "Optimal Radiation of Body-Implanted Capsules," Physical Review Letters, vol. 122, p. 108101, Mar. 2019.

[8] D. Nikolayev, M. Zhadobov, and R. Sauleau, "Impact of Tissue Electromagnetic Properties on Radiation Performance of In-Body Antennas," IEEE Antennas and Wireless Propagation Letters, vol. 17, pp. 14401444, Aug. 2018.

[9] J. Goethals, G. Vermeeren, D. Nikolayev, M. Deruyck, L. Martens, and W. Joseph, "Combined Antenna-Channel Characterization for Wireless Communication from Horse Hoof to Base Station," in 2020 14th European Conference on Antennas and Propagation (EuCAP), (Copenhagen, Denmark), pp. 1-5, IEEE, Mar. 2020.

[10] "IS400."

[11] J. Coonrod and R. Corporation, "Understanding When To Use FR-4 Or High Frequency Laminates," p. 6.

[12] D. J. Dutto, D. F. Hoyt, H. M. Clayton, E. A. Cogger, and S. J. Wickler, "Joint work and power for both the forelimb and hindlimb during trotting in the horse," Journal of Experimental Biology, vol. 209, pp. 3990-3999, Oct. 2006.

[13] Heung-Soo Kim and R. Narayanan, "A new measurement technique for obtaining the complex relative permittivity of terrain surfaces," IEEE Transactions on Geoscience and Remote Sensing, vol. 40, pp. 11901194, May 2002.

[14] M. Soutsos, J. Bungey, S. Millard, M. Shaw, and A. Patterson, "Dielectric properties of concrete and their influence on radar testing," NDT \& E International, vol. 34, pp. 419-425, Sept. 2001.

[15] S. Singha and M. Thomas, "Permittivity and tan delta characteristics of epoxy nanocomposites in the frequency range of $1 \mathrm{MHz}-1 \mathrm{GHz}$," IEEE Transactions on Dielectrics and Electrical Insulation, vol. 15, no. 1, pp. 2-11, 2008.

[16] S. Gabriel, R. W. Lau, and C. Gabriel, "The dielectric properties of biological tissues: III. Parametric models for the dielectric spectrum of tissues," Physics in Medicine and Biology, vol. 41, pp. 2271-2293, Nov. 1996. Publisher: IOP Publishing.

[17] "zurich med tech."

[18] "X.FL Series Connectors - Hirose | DigiKey."

[19] "Equi-Pak Soft ${ }^{\mathrm{TM}}$ 210cc," Nov. 2019. 